\title{
Dei Verbum, notas sobre a construção do texto conciliar ${ }^{1}$
}

\author{
Dei Verbum, notes on the construction \\ of the conciliar text
}

Ney de Souza*

Resumo: O artigo retrata as etapas da elaboração da Constituição Dei Verbum do Concilio Vaticano II. As etapas são as fases de germinação do futuro texto conciliar. O estudo aqui apresentado aborda as inúmeras discussões que ocorreram na assembleia conciliar sobre os esboços elaborados pela Comissão Teológica e refeitos devido às inúmeras intervenções dos bispos presentes no Concílio. Antes de chegar às sessões conciliares o artigo busca as raízes do documento nos albores da modernidade e da ruptura do Cristianismo.

Palavras-Chave: Vaticano II; Dei Verbum; História; Discussões conciliares; Modernidade.

Abstract: This article examines the stages of drafting the constitution Dei Verbum of the Second Vatican Council. As etapas são as fases de germinação do futuro texto conciliar. The steps are the germination stages of future conciliar text. $\mathrm{O}$ estudo aqui apresentado aborda as inúmeras discussões que ocorreram na assembleia conciliar sobre os esboços elaborados pela Comissão Teológica e refeitos devido às inúmeras intervenções dos bispos presentes no Concílio. The present study addresses the numerous discussions that took place at the

\footnotetext{
*Pós-doutorado em Teologia pela Pontifícia Universidade Católica do Rio de Janeiro. Doutor em História Eclesiástica pela Pontifícia Universidade Gregoriana, Roma. Registro USP. Líder do grupo de pesquisa no CNPQ Religião e política no Brasil contemporâneo. Professor da graduação e Pós-Graduação na PUC SP.

Este artigo é resultado com acréscimos da apresentação na Mesa Redonda da Semana Teológica (diurno e noturno) da Pontifícia Universidade Católica de São Paulo (2014).
} 
meeting on reconciling the sketches prepared by the Theological Commission and remade because of the many activities of the bishops present at the Council. Antes de chegar às sessões conciliares o artigo busca as raízes do documento nos albores da modernidade e da ruptura do Cristianismo. Before coming to council sessions Article search the roots of the document in the dawn of modernity and rupture of Christianity.

Palavras-Chave: Vaticano II, Dei Verbum, história, discussões conciliares

Keywords: Vatican II; Dei Verbum; History; Council discussions; Modernity.

\section{Introdução}

Este texto tem por objetivo, em seu primeiro momento, apresentar a germinação de uma Constituição dogmática do Concilio Vaticano II: Dei Verbum. Buscará no início do período moderno estas raízes para no desdobramento seguinte apresentar as longas e acaloradas discussões que ocorreram durante as sessões conciliares. O esquema De Fontibus Revelationis foi introduzido no primeiro período conciliar (1962) e somente aprovado no último (1965) após ser refeito, emendado, discutido e, enfim, aprovado. Os percursos destes debates são de grande importância e reveladores de posturas teológicas diversas que já antecediam o Concilio. Os antecedentes do Vaticano II são anunciadores da situação teológica e das relações da instituição com a sociedade contemporânea ${ }^{1}$. As divergências não nasceram dentro do evento conciliar, mas estão dentro do processo de continuidade e descontinuidade da própria história.

1 SOUZA, N.; GONÇALVES, P. S. Catolicismo e sociedade contemporânea. Do Concílio Vaticano I ao contexto histórico-teológico do Concílío Vaticano II. São Paulo: Paulus, 2013, p. $99-152$. 


\section{Antecedentes históricos (séculos XVI-XIX)}

A mentalidade que foi gestada sobre a Bíblia e a sua leitura encontrou seu ponto máximo na Reforma Protestante (1517). No centro da opção da Reforma estão os axiomas teológicos: sola fide, sola gratia, sola scriptura. A Sagrada Escritura torna-se a única autoridade no que diz respeito à fé e aos costumes, ou seja, cada crente pode interpretar a Escritura ${ }^{2}$.

Neste contexto é realizado o Concílio de Trento (1545-1563) que promulga decretos visando preservar os fiéis. O Concilio afirma que a tradução bíblica da Vulgata, realizada por São Jerônimo é autêntica e isenta de erros. Em nenhum momento afirmou que a tradução bíblica era perfeita, afirmou a ausência de erros no campo teológico pastoral ${ }^{3}$.

A situação pós-conciliar é extremamente complexa na orientação dos fiéis sobre a Escritura. Um dos fatores desta complexidade é a impossibilidade do clero orientar a população de fiéis para a leitura do texto bíblico. Isto se deve a ausência de formação teológica para a maioria dos futuros padres. Trento decretará a instituição de um seminário em cada diocese na busca de solução para resolver a situação da vida de estudos dos clérigos. Devido a esse fator imediato o papa Pio IV (1560-1565), em 1564, lança algumas normas:

a) Somente o bispo pode permitir a pessoas doutas e piedosas a utilização das traduções do Antigo Testamento e mesmo assim somente para esclarecer a Vulgata. Não se permite a utilização das traduções do Novo Testamento, sob a alegação de que elas trariam confusões e pouca utilidade aos leitores;

b) Só o bispo ou o inquisidor pode permitir, a juízo do pároco, a leitura da Bíblia em língua vernácula .

Estas disposições trouxeram consequências sobre o contato dos católicos com a Bíblia, fato este que é um prejuízo até o tempo presente para a evangelização e formação da população de fiéis.

2 ZAGHENI, G. L'età Moderna. Corso di storia dela Chiesa. III. Milano: San Paolo, 1995, p. 120.

3 Cf. Conciliorum Oecumenicorum Decreta. Bologna: EDB, 1991, p. 663s.

4 DENZINGER, H. Enchiridium Symbolorum. Definitionum et declarationum de rebus fidei et moru. Bologna: EDB, 1995, n. 1851-1861. 


\section{Desdobramentos da questão no século $\mathrm{XX}$}

O Movimento bíblico é um antecedente da Dei Verbum. Seu nascimento e desdobramento é sinal de traços da modernidade que configura o novo sujeito eclesial do futuro Concílio Vaticano II.

A exegese bíblica que ficara parada em relação à ciência bíblica protestante, aprendeu desta o aproveitamento das ciências auxiliares, como por exemplo a linguística, a arqueologia e a ciência das religiões comparadas. Passa-se a aceitar a questão dos diversos gêneros literários da Escritura como um elemento para interpretá-la. Em 1947, inicia-se um conjunto de descobertas junto ao Mar Morto, num antigo mosteiro da região de Khirbet Qumrâm, de manuscritos do Antigo Testamento e das Regras de Vida que regulavam a vida de monges de tradição essênia. Estes manuscritos também oferecem uma contribuição para melhor conhecimento da situação sócio religiosa do período da constituição do Novo Testamento. O papa Pio XII (1939-1958) incentiva os trabalhos corajosos dos exegetas católicos, sobretudo os do Pontifício Instituto Bíblico de Roma. Será confessor deste papa o padre Augustin Bea, jesuíta alemão e reitor do Instituto e importante exegeta. Mais tarde será cardeal e um grande protagonista do dialogo ecumênico. Na encíclica Divino Afflante Spiritu (1943) ${ }^{5}$, o papa Pio XII mostra abertura para os diferentes sentidos da Bíblia, os gêneros literários, a liberdade de investigação cientifica no campo bíblico, o estudo das línguas antigas, da arqueologia, da papirologia, da descoberta de novos manuscritos. Neste sentido, abre uma nova era para o estudo da Sagrada Escritura. Em síntese, o movimento bíblico surge da confluência de muitos fatores, implicando uma abertura da exegese às ciências modernas da história, da linguagem e da hermenêutica ${ }^{6}$.

Anteriormente, já no início do século XX, em 1920, o papa Bento XV (1914-1922) para comemorar o $15^{\circ}$ centenário da morte de São Jerônimo publicou a encíclica Spiritus Paraclitus. Na encíclica escreveu o papa

ENCHIRIDION DELLE ENCICLICHE. Vol. 6. N. 261-290. Bologna: EDB, 1995.

6 LIBANIO, J. B. Concílio Vaticano II. Em busca de uma primeira compreensão. São Paulo: Loyola, 2005, p. 22-25. 
Veneráveis irmãos, à imitação de São Jerônimo jamais deixaremos de exortar todos os fiéis cristãos a que leiam todos os dias principalmente os Santos Evangelhos de Nosso Senhor, os Atos e as Epístolas dos apóstolos, tratando de convertê-los em seiva do seu espirito e em sangue de suas veias ${ }^{7}$.

\section{As discussões durante o Vaticano II e a construção da Dei Verbum}

A Dei Verbum, embora apresente muitos elementos sobre a Sagrada Escritura, não é um documento sobre a Bíblia e sim sobre a Revelação divina. "Este Sagrado Concílio...pretende propor a genuína doutrina sobre a Revelação Divina e a sua transmissão, por que, ouvindo o anúncio da salvação, o mundo inteiro creia, crendo espere, esperando ame” (DV, 1).

O processo para a construção deste documento foi longo e conflitivo. Da primeira redação apresentada à última votada, não há nada em comum. Com esta Constituição o Concílio Vaticano II tratou amplamente os grandes temas da fé cristã. O teólogo italiano Rino Fisichella afirma que está longa odisseia no caminho de construção da Dei Verbum começou com a consulta pré-conciliar (1959) e terminou com a promulgação da Constituição no dia 18 de novembro de 1965 (vinte dias antes da conclusão do Concílio). Seu conteúdo marca profundamente a vida da Igreja. A fé e a prática desta fé somente têm sentido na medida em que são a adesão plena à Palavra de Deus ${ }^{8}$.

O trabalho necessário que deveria ser realizado era o de corresponder à exigência de uma harmonização entre os conteúdos da Tradição, irrenunciáveis para a fé e os elementos novos e sua linguagem mais coerente com a nova situação da história da Igreja. As discussões ${ }^{9}$ sobre o esquema da revelaçã $0^{10}$ tiveram debates aca-

ENCHIRIDION DELLE ENCICLICHE. Vol. 4. N. 498. Bologna: EDB, 1998.

FISICHELLA, R. Dei Verbum. In: LATOURELLE, R; FISICHELLA, R. PIÉ-NINOT, S. (dir.). Diccionario de Teologia Fundamental. Madrid: Ediciones Paulinas, 1992, p. 272.

9 AS I/3, p. 55.

10 AS I/3, p. 14-26. Um texto, entre diversos, importante sobre o tema: RUIZ, G. Historia de la constitución 'Dei Verbum' sobre a divina revelación. Madrid, 1969. 
lorados. A discussão girava em torno das duas importantes questões: era necessário afirmar, contra os protestantes, que são duas as fontes da Revelação: a Escritura e a Tradição. Era necessário afirmar que alguns eram dogmas fundamentados somente na Tradição ou afirmar que a única fonte da Revelação é a Palavra de Deus, que é alcançada através de dois canais, a Escritura inspirada pelo Espírito Santo e a Tradição transmitida pela Igreja. Este tipo de afirmação agravaria a situação com os protestantes e ameaçava a reconciliação ecumênica ${ }^{11}$. Estas serão as questões de base discutidas nesta longa e 'calorosa' construção da Dei Verbum.

São três as etapas principais na construção do documento conciliar:

- Primeira etapa: o esquema De fontibus Revelationis

Joa o XXIII (1958-1963) após anunciar o desejo de realizar o Concílio (25/01/1959) nomeou (17/05/1959) uma Comissão antepreparatória presidida pelo cardeal secretário de Estado, Domenico Tardini. A tarefa era a de entrar em contato com o episcopado das diversas nações para obter destes bispos conselhos, sugestões, recolher propostas dos dicastérios da Cúria romana; traçar as linhas gerais dos temas que deveriam ser tratados no Vaticano II. Ouvir as faculdades teológicas e canônicas e as Universidades católicas ${ }^{12}$ era também seu intento. Este tipo de consulta universal nunca havia sido realizado antes.

Estes foram os temas propostos: a natureza da Revelação, a modalidade de transmissão da Revelação e a relação entre magistério e a Palavra de Deus. Essa Comissão era presidida pelo cardeal italiano Alfredo Ottaviani e o secretário era o jesuíta holandês padre Sebastian Tromp, professor de apologética da Pontifícia Universidade Gregoriana em Roma. A comissão era formada por sete membros e dois consultores e redigiu um esboço de esquema como um primeiro plano de trabalho. Título: Schema compendiosum Constitutionis De fontibus Revelationis.

11 SOUZA, N. Contexto e desenvolvimento histórico do Concílio Vaticano II. In: BOMBONATO, V.; GONÇALVES, P. S. L. Concílio Vaticano II. Análise e prospectivas. São Paulo: Paulinas, 2004, p. 38.

${ }^{12}$ Acta et documenta Concilio Oecumenico Vaticano II apparando; series prima, vol. 1 (Antepreparatoria). Città del Vaticano, 1960. p. 23. 
No dia 27 de outubro de 1960 foi constituída uma subcomissão interna presidida por Dom Salvatore Garofano, encarregada de elaborar um esquema sobre as fontes da Revelação. No dia 23 de junho de 1961 estava preparado o texto Schema e este foi enviado para a Comissão Central em 14 de outubro de 1961. Foram feitas numerosas emendas ao texto e finalmente foi aprovado em 22 de junho de 1962. A seguir todo o Schema foi aprovado pelo papa João XXIII no dia 13 de julho de 1962: Schema Constitutionis Dogmaticae De Fontibus Revelationis.

No dia 14 de novembro de 1962 o texto foi debatido na aula conciliar. Contudo, o texto não era o único na sessão deste dia. Ottaviani "falou só cinco minutos, menos apresentando um texto para consideração do que defendendo esse texto, antes mesmo de começar a discussão". Ainda "disse estar ciente de que circulavam esquemas alternativos contrários ao cânon 222 do Código de direito canônico”. Afirmava o cardeal Ottaviani que "a discussão deveria ser sobre esse texto, nenhum outro. No dia anterior ele informara sua comissão que já que os documentos preparados pela Comissão Pré-Conciliar tinham sido aprovados pelo papa o Concílio não podia rejeitá-los"13. A proveniência dos outros esquemas não oficiais que circulavam concomitantemente na Assembleia conciliar eram estas:

a) Um esquema foi preparado pelo Secretariado para a Unidade dos cristãos;

b) Outro esquema preparado pelo teólogo jesuíta Karl Rahner a pedido das conferências episcopais da Áustria, Bélgica, França Holanda e Alemanha. Título De Revelatione Dei et hominis in Jesu Christo facta.

c) Um folheto redigido pelo teólogo dominicano francês Yves Congar. Título: De Traditione et Scriptura.

Com essa situação na Assembleia conciliar era natural que o cardeal Ottaviani durante a apresentação oficial do Schema usasse um tom forte na defesa do texto. O então prefeito do Santo Oficio e presidente da Comissão teológica do Vaticano II até tentou denunciando a presença destes outros três esquemas. No fervor dos debates alguns padres conciliares consideravam o Schema oficial totalmente inaceitável. Dentre

13 O’MALLEY. J. W. O que aconteceu no Vaticano II. São Paulo: Loyola, 2014, p. 154-155. 
os que refutaram o esquema estavam os alemães Augustin Bea, padre jesuíta e depois cardeal, ex-reitor do Biblicum (1930-1949), membro da Comissão Preparatória Central e presidente do Secretariado para a Unidade dos Cristãos ${ }^{14}$; Joseph Frings, presidente da Conferência Episcopal Alemã, arcebispo de Colônia, membro da Comissão Preparatória Central, membro do Conselho de Presidentes, quase cego quando da abertura do Concílio, levou consigo como consultor pessoal Joseph Ratzinger, futuro papa Bento XVI (2005-2013). Sua intervenção mais conhecida foi a crítica ao Santo Oficio ${ }^{15}$; Julius Dofner, arcebispo de Munique e membro da Comissão Central Preparatória, membro da Comissão Coordenadora, autor de um plano para reduzir o número dos esquemas ${ }^{16}$; Franz Konig, cardeal arcebispo de Viena, membro da Comissão Preparatória Central, nomeou Karl Rahner seu teólogo pessoal no Concílio ${ }^{17}$; Jan Bernard Alfrink, cardeal arcebispo de Utrecht, membro da Comissão Preparatória Central, membro do Conselho de Presidentes, líder da maioria ${ }^{18}$. Acusavam o esquema de não aderir a tradição da Igreja e, principalmente, por ser uma contradição com a alocução pontifícia de abertura do Concílio ${ }^{19}$. Havia outros nesta mesma linha como o cardeal Léon-Joseph Suenens, arcebispo de Malines-Bruxelas, membro da Comissão Preparatória Central e da Comissão Coordenadora e o bispo de Bruges Émile-Joseph De Smedt, vice-presidente do Secretariado para a Unidade dos Cristãos que solicitavam uma reelaboração completa e expuseram os pontos fundamentais que deveriam ser considerados no trabalho de revisão. O cardeal Gracias, arcebispo de Bombaim, solicitou uma nova revisão. Nela dever-se-ia afirmar que se poderia constituir base de anúncio do Cristianismo toda a humanidade; cristãos e não cristãos. O chinês Vito Chang Tso-Huan, seguindo uma observação do arcebispo de Berlim, Bengsch, interrogou sobre a

\footnotetext{
O'MALLEY. Op. cit. p. 327.

O'MALLEY. Op. cit. p. 329.

O'MALLEY. Op. Cit. p. 328.

O’MALLEY, op. cit. p. 329.

O'MALLEY. Op. Cit. 327.

AS, I/3, p. 48-51.
} 
possibilidade de se falar sobre a revelação original, a 'proto-revelação', antes daquela realizada por Abraão ao povo eleito ${ }^{20}$.

Na opinião do bispo de Livorno, D. Emiliano Guano, era preciso ressaltar a importância cristológica, sugerindo a reconstrução inicial e fundamental do capítulo sobre o duplo reconhecimento da centralidade do mistério de Cristo, por um lado, e o papel insubstituível da Escritura e da vida cristã para o concreto testemunho da revelação, por outro ${ }^{21}$. O cardeal Giovanni Urbani ${ }^{22}$, patriarca de Veneza, porta-voz dos moderados italianos, apresentou a proposta sobre o estilo do texto: deveria ser mais pastoral e ecumênico.

Outros, nesta sessão, afirmavam que o texto possuía lacunas e havia a necessidade de uma transformação radical. O cardeal Ernesto Ruffini, arcebispo de Palermo e porta-voz frequente da minoria, afirmava que era indispensável uma exposição precisa sobre a natureza da revelação ${ }^{23}$. Segundo De Mattei, que segue uma linha historiográfica diversa deste texto, "a resposta mais articulada dos conservadores foi dada por D. Geraldo de Proença Sigaud, que afirmou que os gravíssimos erros condenados por Pio XII na encíclica Humani generis continuavam vivos, e contaminavam a Igreja com seu veneno"24. Dom Geraldo era bispo de Diamantina, em Minas Gerais, Brasil, membro da Sociedade da Palavra Divina, fundador do Grupo de Padres Internacionais (Coetus) e porta-voz das posições do grupo ${ }^{25}$.

As motivações para repudiar o texto estavam especialmente no seu $1^{\circ}$ capítulo: impropriedade e equívoco de linguagem e pensamento levavam a consequências doutrinais que viam a Escritura e a Tradição como fontes independentes uma da outra. Assim, vários padres conciliares criticavam a opção teológica unilateral assumida pela Comissão.

20 AS I/3 p. 166-167; 267-268; 87-88, nesta ordem estão as declarações de Gracias, Vito Chang e Bengsch.

21 AS I/3 p. 260-262. Sobre Emiliano Guano confira: MONTICONE, A. Dizionario storico del Movimento Cattolico in Italia 1860-1980. Torino, 1982. V. 2, p. 280-284.

22 AS I/3 p. 79-80.

23 AS I/3 p. 249-250.

24 DE MATTEI, R. O Concílio Vaticano II. Uma história nunca escrita. São Paulo: Ambiente \& Costumes, 2013, p.221.

${ }^{25}$ Sobre as posições deste grupo Coetus, confira: CALDEIRA, R. C. Os Baluartes da tradição. O conservadorismo católico brasileiro no Concílio Vaticano II. Curitiba: Editora CRV, 2011. 
Foram muitas as vozes críticas na Basílica de São Pedro. A temática "era um importante ponto de discórdia entre católicos e protestantes, desde a insistência de Lutero em que a Escritura era a única base da verdade cristã". Para fortalecer a discussão este esquema "que citava o Concílio de Trento como principal justificativa, afirmava que algumas verdades encontravam-se na Escritura; outras, entretanto, encontravam-se na Tradição, e estas eram as verdades que os autores do Novo Testamento não puseram por escrito" ${ }^{26}$. Mesmo assim, envoltos nesta polêmica, foi realizada a votação. A pergunta feita aos padres era: É necessário interromper a discussão sobre o esquema da Constituição dogmática sobrea as fontes da revelação? Está era uma pergunta bastante vaga: a suspensão equivale a rechaçar o texto ou o debate do mesmo texto deveria continuar em outro momento?

A Comissão Teológica, que havia preparado este esquema De Fontibus demonstrou um repúdio às sugestões que foram oferecidas pela maioria $^{27}$, porém o Conselho da presidência decidiu realizar a votação pedindo aos padres conciliares que votassem placet ou non placet ao item.

No dia 20 de novembro de 1962 a votação obteve o seguinte resultado: 2209 eleitores votantes, 1368 placet, 822 non placet e 19 nulos. Faltavam 115 votos para a maioria. Juridicamente não se alcançou o quórum de $2 / 3$, mas com essa votação a continuidade do debate estava totalmente comprometida. Os opositores do esquema não conseguiram chegar à maioria dos dois terços, necessária para uma nova formulaçã $0^{28}$. Contudo, havia ficado claro que o esquema, como havia sido redigido, jamais obteria a aprovação. João XXIII retirou da discussão o texto ${ }^{29}$ e só voltaria quando estivesse totalmente emendado.

- Segunda etapa: o texto da Comissão "mista”.

Por decisão do papa João XXIII a remodelação radical do texto foi incumbida de ser realizada por uma Comissão especial formada por membros da Comissão Central e membros do Secretariado para

\footnotetext{
26 O’MALLEY. Op. Cit. p. 156.

27 AS I/3 p. 220.

28 AS I/3 p. 254-255.

29 LABOA, J. M. Historia de la Iglesia Católica. V, Edad Contenporánea. Madrid: BAC, 2004, p. 485.
} 
a Unidade dos Cristãos ${ }^{30}$, com consultores e cardeais designados pelo próprio papa. Devido a este formato a Comissão foi designada de "mista". Era seu presidente os cardeais Alfredo Ottaviani e Augustin Bea; seus secretários eram o padre Tromp e o futuro bispo Johannes Willebrandes, da diocese de Haarlem (Países Baixos). Enquanto Ottaviani era considerado o líder da minoria, Bea era importante líder da maioria dos padres conciliares. Era portador de uma formação e experiência muito maior de quase todos os "romanos", obviamente, estes não compartilhavam sua perspectiva ${ }^{31}$. A tarefa desta Comissão seria “emendar o esquema, abreviá-lo e torná-lo mais apropriado com ênfase especialmente em princípios gerais” ${ }^{2}$. Será que funcionaria uma Comissão presidida pelos cardeais Ottaviani e Bea? O esquema continuou dentro de histórias agitadas por longos três anos. Somente foi aprovado, como a Constituição Dogmática Dei Verbum em 18 de novembro de 1965, algumas semanas antes do término do Concílio.

A Comissão iniciou seus trabalhos realizando uma subdivisão em cinco outras subcomissões, após ter se colocado de acordo sobre a estrutura do texto, denominado De Divina Revelatione. Necessitava de um Proêmio para colocar em evidência a doutrina sobre a Revelação. Aceitava-se a troca do título do I capítulo. Antes era De duplicis Fonte Revelationis a passou a ser De Verbo Dei Revelatio. Deste modo, a Comissão centrou suas atividades sobre o Proêmio e o I capítulo. As discussões buscaram redigir um texto que tratasse da relação do depósito revelado com a Igreja em geral e com o Magistério em particular. Em 27 de março de 1963, depois de passar pela Comissão de coordenação, o texto foi aprovado e enviado aos padres conciliares.

O texto não agradou. Era fruto de diversos compromissos assumidos durante a sua composição. O texto deveria ser remodelado sem suprimir a sua estrutura fundamental. Novamente o texto deveria ser rechaçado. "Somente depois que o documento foi totalmente descartado e um novo composto quase a partir do zero para o terceiro período, o assunto da 'palavra de Deus' (Dei Verbum) chegaria à tribuna do

\footnotetext{
$30 \quad$ AS I/3 p. 259.

31 O’MALlEY, J. W. O que aconteceu no Vaticano II. São Paulo: Loyola, 2014, p. 128.

32 AS I/3, 259.
} 
Concilio" ${ }^{33}$. Em 7 de março de 1964 foi constituída uma subcomissão dentro da Comissão doutrinal. Dom André-Marie Charue, bispo de Namur (Bélgica) foi o presidente e o padre Umberto Betti o secretário.

- Terceira etapa: A elaboração do novo texto.

Os peritos trabalharam muito nesta etapa. "Deviam buscar a concordância das inúmeras observações que chegavam constantemente dos padres conciliares, transformando-as num texto que fosse a expressão de todo o Concílio"34. O novo texto compreendia um Proêmio. Sua finalidade era oferecer um tom pastoral a todo o esquema. Eram seis capítulos: 1) De ipsa revelatione; 2) De Divinae revelationis; 3) De sacrae Scripiturae divina inspiratione et interpretatione; 4) De Vetere Testamento; 5) De Novo Testamento; 6) De sacra Scriptura in vita Ecclesiae.

O papa Paulo VI inaugurou o $3^{\circ}$ período conciliar em 14 de setembro de 1964. Os padres conciliares já estavam acostumados aos debates. A discussão do texto foi realizada de 30 de setembro a 6 de outubro. Foi estudado em duas partes: primeiro o Proêmio e os dois primeiros capítulos. A seguir se deu a discussão dos demais capítulos. A avaliação dos padres foi positiva e, o texto tendo assimilado as observações, foi totalmente reformado em relação às edições anteriores. O texto denuo emendatus foi entregue aos padres para ser submetido à votação. A votação no $3^{\circ}$ período contemplava a opção placet iuxta modum (que recebeu 1498 votos). Dada essa votação é possível imaginar o grande trabalho para o pequeno número de peritos. 0 número resistente da minoria diminuiu quando, por desejo do papa, precisou-se a infalibilidade da Escritura ${ }^{35}$. Novamente foi definida a relação entre Escritura e tradição. O cardeal de Gênova, Giuseppe Siri, desejava que fosse clara a questão da tradição e que a tradição e o magistério da Igreja fossem colocados acima de todos os meios hermenêuticos ${ }^{36}$. A tradição é o magistério vivo da Igreja, o qual tem autoridade para interpretar e integrar a Escritura. São confirmados a doutrina de inspiração e o caráter histórico dos evangelhos.

33 O’MALLEY. Op. Cit. p. 175.

34 LOPES, G. Dei Verbum Texto e comentário. São Paulo: Paulinas, 2012, p. 56.

35 CAPRILE, G. Tre emendamenti allo schema sulla rivelazione. In: CivCatt 117 (1966) p. 214-231.

36 AS V/3 p. 352-355. 
O texto devidamente corrigido e emendado pode ser entregue para a votação na Assembleia em 29 de outubro de 1965: 2215 votantes; 2081 placet, 27 non placet e 7 nulos. Na sessão pública em 18 de novembro de 1965 estavam presentes para a promulgação 2350 votantes, 2344 placet, 6 non placet ${ }^{37}$. Recebendo a assinatura do papa Paulo VI e de todos os padres conciliares presentes eis que nasce, após inúmeras labutas e turbulências, a Constituição Dogmática Dei Verbum. O Vaticano II "evitou a leitura ingênua e fundamentalista da Escritura, levando em consideração os 'gêneros literários', a intenção do hagiógrafo, o modo em que a verdade é expressa, as circunstâncias, as condições de tempo e cultura do texto e outros aspectos metodológicos”38.

\section{Considerações finais}

Recebendo a assinatura do sucessor de Pedro e dos padres conciliares presentes, o documento se tornou a Constituição Dogmática Dei Verbum. Seu trajeto de construção passou por inúmeras vicissitudes, foram 6 redações, passando por todas as etapas do Concílio. A Constituição Dei Verbum entra para o patrimônio do ensinamento católico. Suas consequências não são inovadoras, mas renovadoras. Segundo o papa Paulo VI está Constituição era o começo de muitas coisas novas para a vida da Igreja.

Ao término deste estudo se relembra as palavras de São João XXIII que ao ser interpelado por um jornalista que lhe perguntava 0 que ele desejava ao definir o Concilio como "uma janela para o mundo", sorrindo, o papa respondeu: "Para entrar ar puro".

\section{Bibliografia}

AA - Acta et documenta Concilio Oecumenico Vaticano II apparando; series prima, vol. 1 (Antepreparatoria). Città del Vaticano, 1960-1961. 4 volumina.

\footnotetext{
$37 \quad$ AS IV/5 p. 751-753.

38 LIBANIO, J. B. Concílio Vaticano II. Em busca de uma primeira compreensão. São Paulo: Loyola, 2005, p. 98.
} 
AS - Acta Synodalia Sacrosancti Concilii Vaticano II. Città del Vaticano, 1970-1991. 5 volumina.

BOMBONATO, V. - GONÇALVES, P. S. L. (org.). Concílio Vaticano II. Análise e prospectivas. São Paulo: Paulinas, 2004, p. 17-67.

CALDEIRA, R. C. Os Baluartes da tradição. O conservadorismo católico brasileiro no Concílio Vaticano II. Curitiba: Editora CRV, 2011.

CAPRILE, G. Ter emendamenti allo schema sulla rivelazione. In: CivCatt 117 (1966) p. 214-231.

DE MATTEI, R. O Concílio Vaticano II. Uma história nunca escrita. São Paulo: Ambiente \& Costumes, 2013.

DENZINGER, H. Enchiridium Symbolorum. Definitionum et declarationum de rebus fidei et moru. Bologna: EDB, 1995.

ENCHIRIDION DELLE ENCICLICHE. Vol. 6. N. 261-290. Bologna: EDB, 1995.

ENCHIRIDION DELLE ENCICLICHE. Vol. 4. N. 498. Bologna: EDB, 1998.

FISICHELLA, R. Dei Verbum. In: LATOURELLE, R; FISICHELLA, R. PIÉ-NINOT, S. (dir.). Diccionario de Teologia Fundamental. Madrid: Ediciones Paulinas, 1992.

LABOA, J. M. Historia de la Iglesia Católica. V, Edad Contenporánea. Madrid: BAC, 2004.

LIBANIO, J. B. Concílio Vaticano II. Em busca de uma primeira compreensão. São Paulo: Loyola, 2005.

LOPES, G. Dei Verbum Texto e comentário. São Paulo: Paulinas, 2012.

MONTICONE, A. Dizionario storico del Movimento Cattolico in Italia 18601980. Torino, 1982. V. 2, p. 280-284.

O’MALLEY. J. W. O que aconteceu no Vaticano II. São Paulo: Loyola, 2014. RUIZ, G. Historia de la constitución 'Dei Verbum' sobre a divina revelación. Madrid, 1969.

SOUZA, N. Contexto e desenvolvimento histórico do Concílio Vaticano II. In: BOMBONATO, V.; GONÇALVES, P. S. L. Concílio Vaticano II. Análise e prospectivas. São Paulo: Paulinas, 2004.

SOUZA, N.; GONÇALVES, P. S. Catolicismo e sociedade contemporânea. Do Concílio Vaticano I ao contexto histórico-teológico do Concílío Vaticano II. São Paulo: Paulus, 2013.

ZAGHENI, G. L'età Moderna. Corso di storia della Chiesa. III. Milano: San Paolo, 1995.

Recebido em: 18/04/2015

Aprovado em: 09/05/2015 